\title{
Análisis geomorfológico y dinámica fluvial del río Huallaga en la localidad de Yurimaguas
}

Recibido: 29/04/2020

Aprobado: 04/05/2020

Publicado: $25 / 08 / 2020$
Robert B. Ramos Alonzo

Universidad Nacional Mayor de San Marcos <rramosa@unmsm.edu.pe>

Miguel E. Alva Huayaney Universidad Nacional Mayor de San Marcos <malvah@unmsm.edu.pe>

\begin{abstract}
RESUMEN
El río Huallaga es uno de los principales ríos amazónicos. El área de investigación ubicada en la llanura amazónica se caracteriza por presentar un relieve homogéneo, sin embargo por la dinámica del río el aspecto fisiográfico es variado, estos van desde las zonas inundables hasta zonas más elevadas denominadas colinas. El régimen del caudal varía a lo largo del ańo evidenciándose meses de estiaje y otros de abundante recarga, el caudal promedio es de $2969.5 \mathrm{~m}^{3} / \mathrm{s}$, en el área de investigación el ancho promedio es de $325 \mathrm{~m}$ y presenta una profundidad máxima de $16 \mathrm{~m}$. Por sus dimensiones, el río Huallaga presenta un gran dinamismo, evidenciándose que en el período de análisis se ha producido en un sector, que este, ha cambiado su dirección dejando un cauce abandonado, la dinámica es a lo largo de su lecho notándose que en las zonas en donde el río cambia de dirección, esta ha migrado incluso hasta más de $2 \mathrm{~km}$.
\end{abstract}

Palabras clave: Fisiografía, dinámica fluvial, caudal, migración meandrica.

\section{Geomorphological analysis and fluvial dynamics of the Huallaga River in Yurimaguas distric}

\begin{abstract}
The Huallaga River is one of the main Amazon rivers. The research area located in the Amazon plain is characterized by presenting a homogeneous relief, however due to the dynamics of the river the physiographic aspect is varied, these range from the flood areas to higher areas called hills. The flow regime varies throughout the year, showing months of low water and others with abundant recharge, the average flow is $2969.5 \mathrm{~m} 3 / \mathrm{s}$, in the research area the average width is $325 \mathrm{~m}$ and has a maximum depth of $16 \mathrm{~m}$. Due to its dimensions, the Huallaga river presents a great dynamism, evidencing that in the period of analysis it has occurred in a sector, which has changed its direction, leaving an abandoned channel, the dynamics is along its bed, noting that in the areas where the river changes direction, it has migrated even up to more than $2 \mathrm{~km}$.
\end{abstract}

KeYwords: Physiography, fluvial dynamics, flow, meandering migration. 
a cuenca hidrográfica del río Amazonas es la más grande del mundo. Su vertiente cubre alrededor de 6,0 millones de $\mathrm{km}^{2}$ y su caudal medio es el mayor del mundo, estimado en $209000 \mathrm{~m}^{3} / \mathrm{s}$ (Moliner et al., 1996). Como se evidencia, esta cuenca es bastante extensa por lo que es posible identificar diversas regiones climáticas traducidas en una variabilidad de las descargas de la precipitación y del régimen hidrológico.

En el Perú, el área de la cuenca del río Amazonas es de $750000 \mathrm{~km}^{2}$, en la estación hidrométrica de Tamshiyacu el río Amazonas, presenta un caudal medio de $32000 \mathrm{~m}^{3} / \mathrm{s}$, aproximadamente este representa el 16\% del caudal (Espinoza et al., 2014). Sus dos principales tributarios son el río Marañon y el río Ucayali, ambos tienen un origen andino a través de sus tributarios.

El río Huallaga es el más importante afluente del río Marañón por su margen derecha. Tiene sus nacientes en el departamento de Pasco, al sur de la cordillera de Raura, en la laguna Huascacocha a $4710 \mathrm{msnm}$, presenta una longitud aproximada de $1389 \mathrm{~km}$. En su recorrido cruza diversas regiones geográficas expresadas fundamentalmente en su gradiente altitudinal, en el sector alto de la cuenca el río desciende sobre un cause estrecho dominado por flancos rocos, en el sector medio el río cruza por valles más amplios y luego de cruzar el Pongo de Aguirre el río se vuelve más sinuoso ya que recorre la llanura amazónica (Carranza, 2011).

La dinámica del río Huallaga se explica por las características geológicas y climáticas; el primero define la base del aspecto del relieve expresada en la llanura amazónica (cuenca baja) y en el aspecto montañoso (cuenca media y alta), el segundo condiciona la disponibilidad de agua a través de las descargas de la precipitación, siendo muy abundante en la región amazónica, la cordillera de los andes define que el flanco oriental presente pendientes considerablemente elevadas, por lo que en el sector medio y alto los ríos son muy torrentosos y en su recorrido transportan alto contenido de material arrancado de las riberas.

\section{Ubicación}

El área de investigación se ubica en las coordenadas

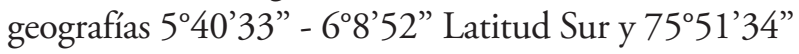
- $76^{\circ} 17^{\prime} 3^{\prime \prime}$ Longitud Oeste, políticamente se ubica en

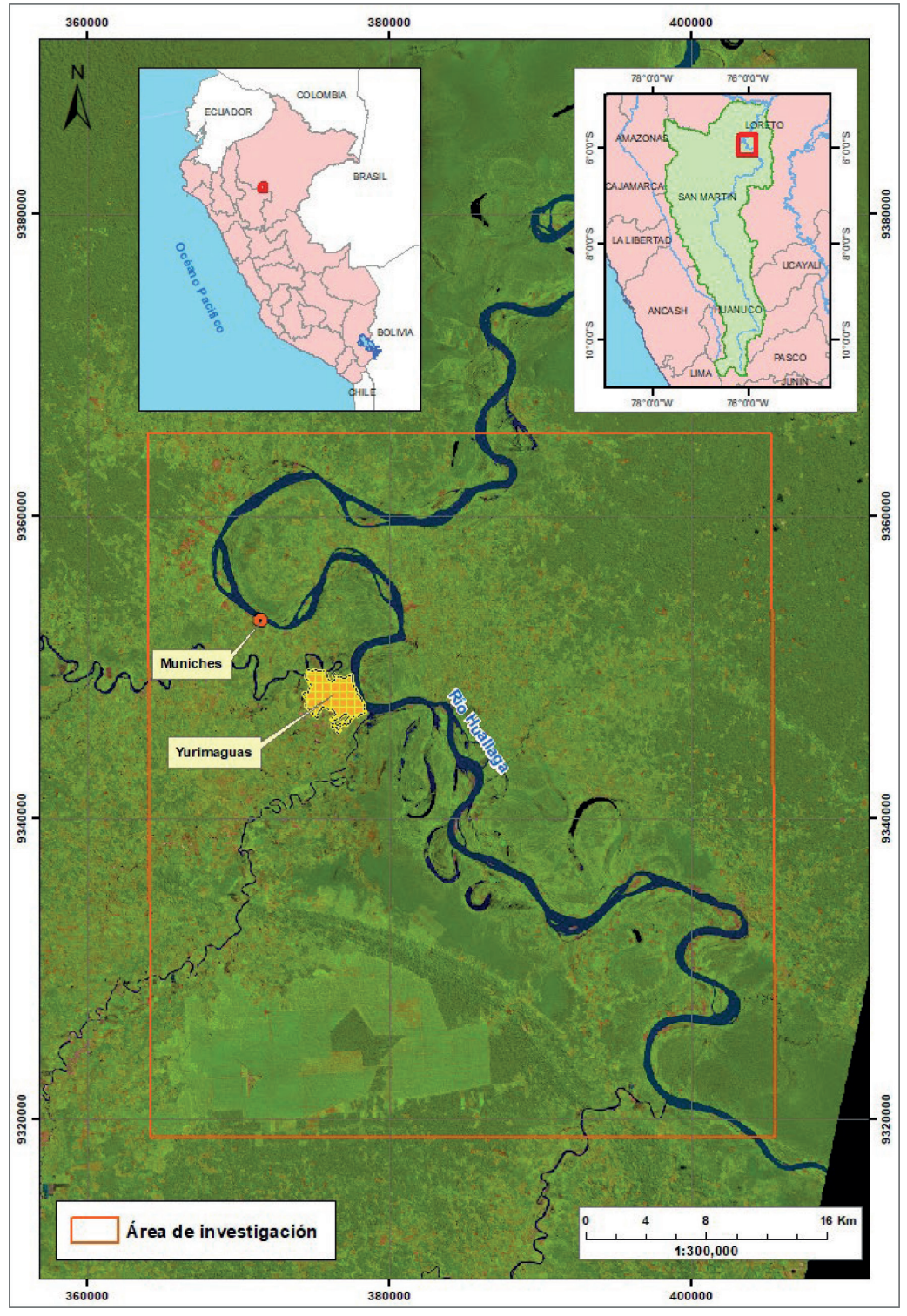

Figura 1: Mapa de ubicación del área de investigación

Fuente: Elaboración propia

el distrito de Yurimaguas, provincia de Alto Amazonas, región Loreto en el llano amazónico, región caracterizada por presentar enormes volúmenes de evapotranspiración producto de las intensas precipitaciones y temperaturas considerablemente elevadas, por estas características en una región de gran biodiversidad.

\section{Geomorfología}

Tradicionalmente la Geomorfología se ha ocupado de los estudios a escala media en los que se anali- 
zan los diferentes eventos geomorfológicos que han configurado, a lo largo del tiempo, el relieve actual (Gutiérrez, 2008). Por lo que en esta sección se definen la forma del relieve, su origen y los procesos que se vienen desarrollando sobre la superficie.

\section{Orogénesis}

Almeida (1982) indica que, para su origen, la desviación E-W del continente sudamericano provocó un choque entre su zócalo (el escudo guyano-brasileño) y la placa oceánica que tiende a hundirse hacia el Este. El frente de choque N-S corresponde más o menos al eje actual de los Andes. Las dos masas antagónicas fueron intensamente fracturadas a lo largo de este frente, lo que permitió al magma profundo ascender hacia la superficie.

Sourdat (1982) precisa que durante el Cretáceo (entre 140 y 60 M.A. a.p. ${ }^{1}$ ) se produjo el surgimiento de los Andes, generando una elevación parcial respecto del escudo Guyano-brasileño (GB). Durante el Eoceno (entre 50 y 35 M.A. b.p.), se produciría un empuje vertical, que generaría el primer levantamiento significativo de los Andes lográndose establecer una separación de la fosa interandina. El levantamiento se produce a través de bloques orientados presentando una dirección general Sur-Norte, estos bloques se muestran a modo de pedazos sedimentarios y material granítico de origen magmático. En esta región el sinclinal ubicado entre los Andes y el escudo GB se termina de deformar para luego ser rellenado de manera alternada de sedimentos continentales, marinos y lagunares.

Finalmente, durante el Mio-plioceno (entre 25 y 1,5 M.A. b.p.), el proceso tectónico define un nuevo empuje vertical generando fracturas, hundimientos y actividad volcánica. La cordillera oriental y occidental terminan de presentar sus características actuales, en la zona de piedemonte se evidencia la fosa interandina. El geosinclinal del Este, en donde el plegamiento se encontraba en pleno proceso, emerge dando origen a las cordilleras subandinas y al relieve de la región.

\section{Fisiografía}

Para la identificación de las unidades fisiográficas se ha seguido lo establecido por el sistema CIAF de clasificación fisiográfica (Villota, 2005), y adaptada al área de investigación, identificando dos grandes paisajes, tres paisajes y cinco sub-paisajes.

\begin{tabular}{|c|c|c|c|}
\multicolumn{4}{|c}{ TABLA 1. Unidades fisiográficas } \\
\hline \multirow{1}{*}{ Gran paisaje } & Paisaje & Sub-paisaje & Símbolo \\
\hline \multirow{4}{*}{$\begin{array}{c}\text { Llanura } \\
\text { amazónica o } \\
\text { selva baja }\end{array}$} & $\begin{array}{c}\text { Llanura } \\
\text { amazónica } \\
\text { inundable }\end{array}$ & $\begin{array}{c}\text { Terrazas bajas } \\
\text { eventualmente } \\
\text { inundables }\end{array}$ & Tb-ei \\
\cline { 3 - 4 } & $\begin{array}{c}\text { Terrazas } \\
\text { depresionadas }\end{array}$ & Td \\
\cline { 3 - 4 } & $\begin{array}{c}\text { Llanura } \\
\text { amazónica no } \\
\text { inundable }\end{array}$ & $\begin{array}{c}\text { Terrazas } \\
\text { medias }\end{array}$ & Tm \\
\cline { 3 - 4 } & Terrazas altas & $\mathrm{Ta}$ \\
\hline Montaña & Montaña baja & Colinas & $\mathrm{Co}$ \\
\hline
\end{tabular}

Fuente: Adaptado de Villota, 2005

\section{Llanura amazónica o Selva Baja}

Este gran paisaje, ocupa la parte oriental del territorio peruano, es conocido también con el nombre de Selva baja, comprende la gran depresión amazónica del continente sudamericano, presenta relieves dominantemente homogéneos, cubiertos por una densa vegetación tropical.

El clima en esta región es húmedo y caluroso, donde la temperatura promedio está próximo a $26^{\circ} \mathrm{C}$, con valores máximos que pueden superan los $31^{\circ} \mathrm{C}$; la precipitación total anual esta próxima a 2 $700 \mathrm{~mm}$.

\section{Llanura amazónica inundable}

Este paisaje se ubica en las zonas próximas al río Huallaga, conformando depósitos cuaternarios recientes y sub-recientes de origen aluvial. Están conformados por el nivel más bajo del llano amazónico, los mismos que vienen evolucionando conforme son cubiertas periódicamente por las crecientes estacionales. 
Islas

Las islas se encuentran en el curso del río Huallaga, a lo largo del tramo de investigación se han identificado más de siete islas. Se originan generalmente cuando el caudal y velocidad del río disminuye, esto da como resultado la acumulación de sedimentos formando islas, en estas zonas se acumulan también las palizadas que arrastran los ríos, estos materiales obstruyen su cauce provocando la acumulación constante de sedimentos. Estas islas se pueden dividir en las temporales que aparecen y desaparecen según la dinámica del río, y otros que son mucho más estables definido básicamente por su mayor extensión, por estas características es posible identificar una cobertura vegetal propia.

\section{Terrazas bajas eventualmente inundables}

Son superficies llanas con pendientes inferiores a $2 \%$, que conforman el nivel más bajo del sistema de terrazas aluviales de la región. En el área de investigación, estas superficies presentan alturas de hasta 2 metros con relación al nivel de estiaje del río Huallaga, así como una configuración alargada y amplitud variable (entre $700 \mathrm{~m}$ a $3 \mathrm{~km}$ desde la margen del río) y más o menos paralela al lecho fluvial. Litológicamente, se encuentran conformados por bancos inconsolidados de arenas, limos y arcillas.

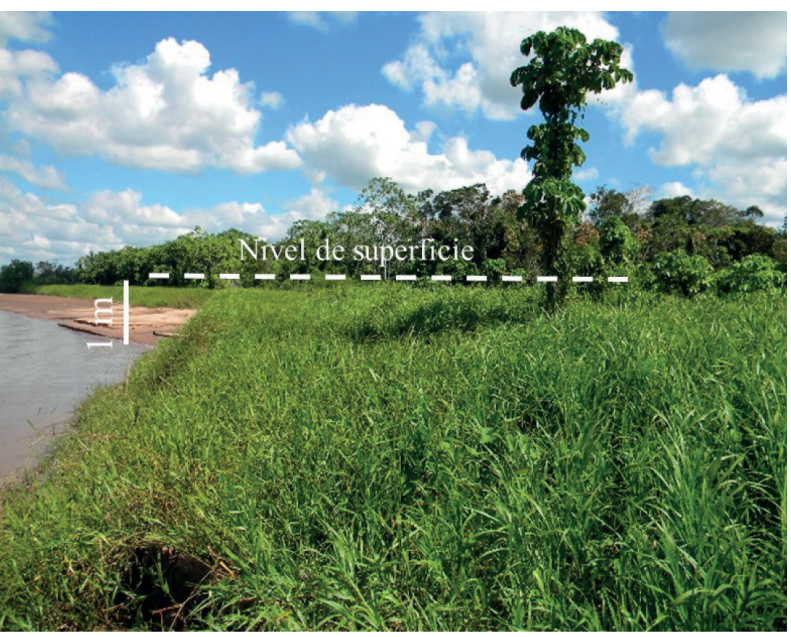

Figura 2: Terrazas bajas en la margen izquierda del río Huallaga Fuente: Ramos Robert, 2018

\section{Terrazas depresionadas}

Son relieves cóncavos de 0 a $1 \%$ de pendiente caracterizados por su drenaje pobre además de presen- tar serios problemas de hidromorfismo permanente debido a la influencia de la inundación anual. Por estas características el nivel del agua sub-superficial presenta una oscilación constante y aflora en la superficie especialmente después de períodos lluviosos. Por su superficie depresionada estas terrazas acumulan las aguas de precipitación pluvial y las que se acumulan durante las inundaciones fluviales.

Presentan un substrato rocoso impermeable y un manto sedimentario superficial constituido por arcillas y limos de color grisáceo a marrón oscuro.

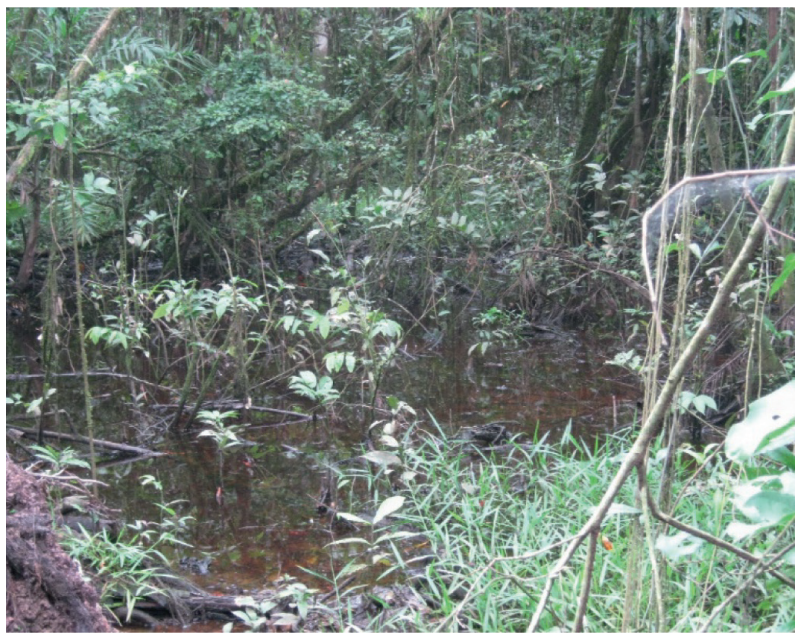

Figura 3: Terrazas depresionadas cubiertas de agua /

Fuente: Ramos Robert, 2018

\section{Llanura amazónica no inundable}

Son relieves llanos que a diferencia del paisaje anteriormente descrita no presentan problemas de inundación. Están conformados mayormente por depósitos cuaternarios sub-recientes. Este relieve está formado por terrazas que actualmente ocupan posiciones altas, lo que no permite que sean inundables.

\section{Terrazas medias}

Esta unidad, comprende a un sistema de terrazas relativamente reciente; caracterizándose por presentar una topografía llana a ligeramente ondulada de 0 a $2 \%$ de pendiente, se ubica entre 3 a 5 metros por encima del nivel de estiaje por lo que la superficie no presenta problemas de inundación. Esta unidad consiste en depósitos cuaternarios aluviales y fluviales constituidos por sedimentos finos, arenosos a areno-arcillosos. 


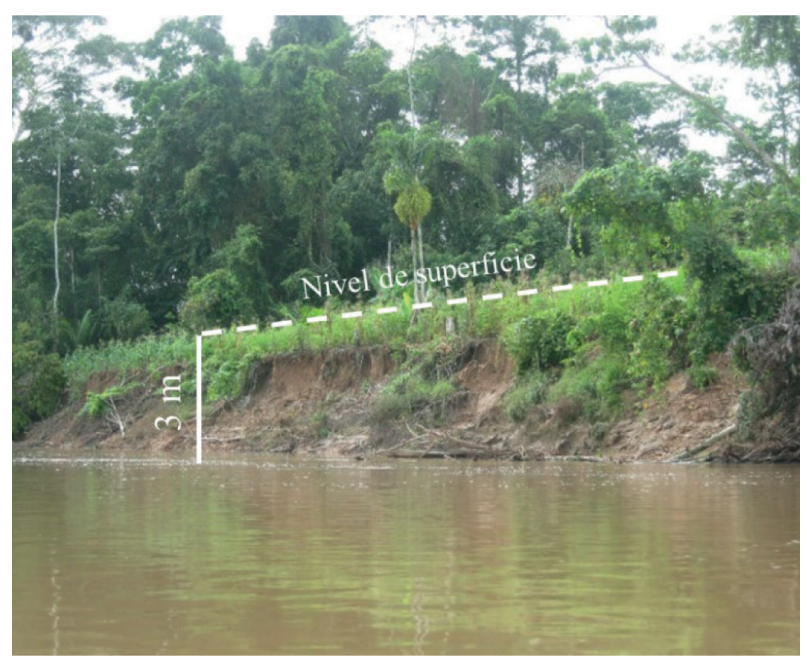

Figura 4: Terrazas medias con cultivos sobre las márgenes del río Huallaga

Fuente: Ramos Robert, 2018

\section{Terrazas altas}

Son terrazas antiguas con una topografía casi plana, presenta una pendiente considerablemente baja. Constituyen las terrazas de mayor elevación que alcanzan una altura de 5-10 metros con respecto al nivel del estiaje del río Huallaga, por lo que no son afectadas por las inundaciones estacionales.

Litológicamente las terrazas altas se conforman de secuencias inconsolidadas de limoarcillitas, limoarenosas, limos y arenas. Son superficies que se encuentran expuestas a erosión difusa debido a las elevadas precipitaciones que ocurren en la región.

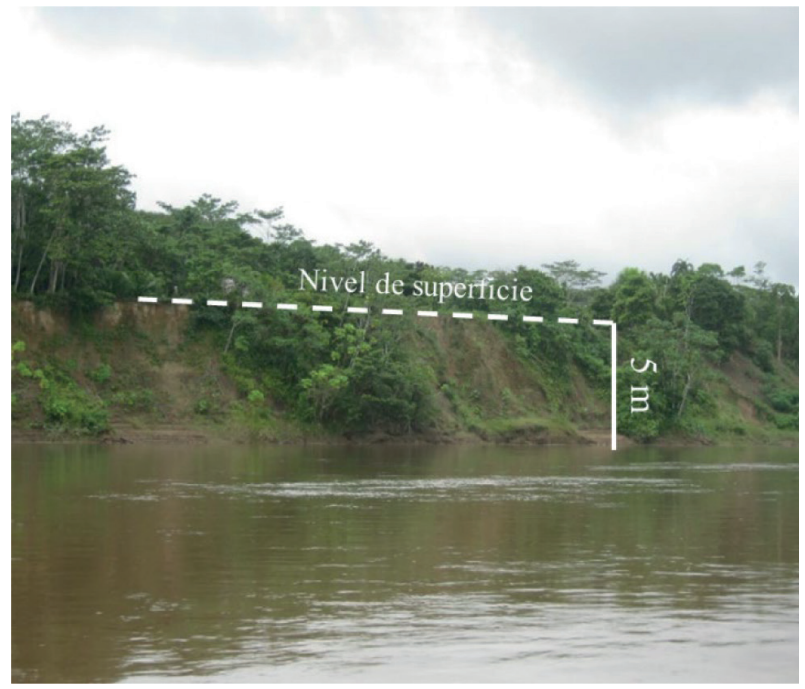

Figura 5: Terrazas altas en las márgenes del río Huallaga

Fuente: Ramos Robert, 2018

\section{Montaña Baja}

Es parte de la región andina que cruza al territorio peruano con dirección general Sur-Norte, por sus dimensiones define el carácter geográfico y climático de una gran región. Este paisaje se ubica en la vertiente oriental de los andes con grandes contrastes geográficos (pendiente y altitud) que van desde las primeras estribaciones hasta el contacto con la región denominada ceja de selva.

La precipitación supera los $3000 \mathrm{~mm}$ al año, debido a ello y a su carácter geográfico es una región generadora de sedimentos y materiales litológicos, sin embargo la abundante cobertura vegetal reduce que los procesos erosivos sean intensos.

\section{Colinas}

Son relieves de morfología ondulada, con elevaciones que pueden superar los 100 metros y pendientes que oscilan entre 8 y 15\%, hallándose caracterizados por un drenaje relativamente importante. Su origen de tipo denudacional, es resultado del desgaste pronunciado de relieves preexistentes, conformados por rocas sedimentarias terciarias, blandas y poco coherentes, de las formaciones Chambira e Ipururo.

Estas geoformas presentan un potencial de erosión mayor que las terrazas medias y altas debido a su topografía. Así mismo se evidencia que en diversos sectores del área de investigación procesos intensos de deforestación que expone al relieve a procesos erosivos denominados erosión difusa.

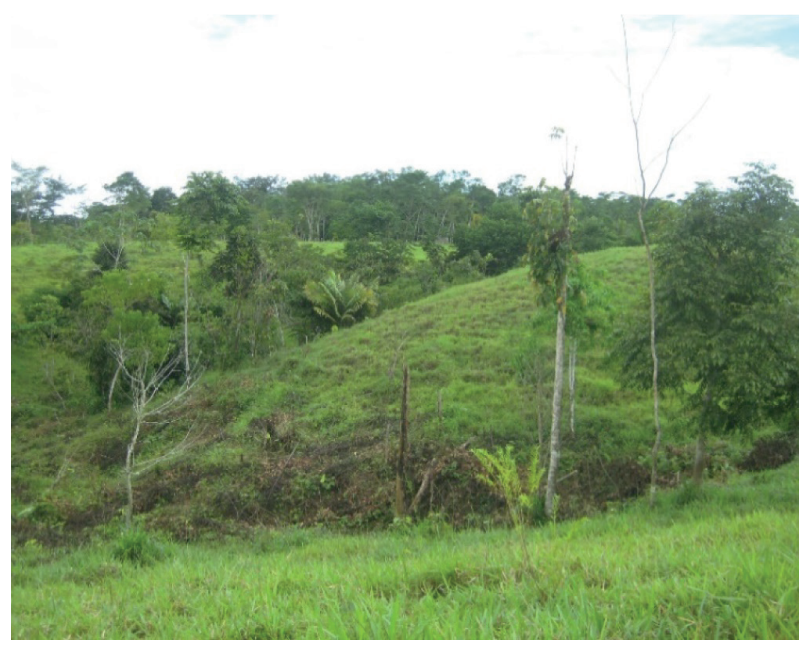

Figura 6: Colinas bajas deforestadas

Fuente: Ramos Robert, 2018 


\section{Procesos morfodinámicos}

Los procesos morfodinámicos están asociados a una secuencia conformada por la erosión de las rocas, el transporte de los materiales removidos y la sedimentación de dichos detritos. Dependen de una serie de factores externos relacionados con la energía del agente morfogenético y la posición geomorfológica (Universidad de Chile - Instituto de Geografía).

Por las características del área de investigación se identifican dos tipos de procesos morfodinamicos.

\section{Desbordes e inundaciones}

Son acciones morfodinámicas que se producen durante las temporadas de lluvias (enero-abril). Durante estos meses, el río Huallaga y sus tributarios incrementan notablemente su caudal sobrepasando sus cauces e inundando parcial o totalmente los terrenos aledaños y el sistema de terrazas bajas. Es de resaltar la inundación que ocurrió en el año 2007 en donde por el incremento del caudal el río Huallaga inundo grandes sectores de las terrazas bajas y depresionadas.

Normalmente son desbordes de agua tranquilos por lo que los procesos de inundación son paulatinos y toman un tiempo relativamente considerable. En sus máximas crecidas pueden incrementar su nivel de altura hasta $3 \mathrm{~m}$ respecto al nivel medio del agua.

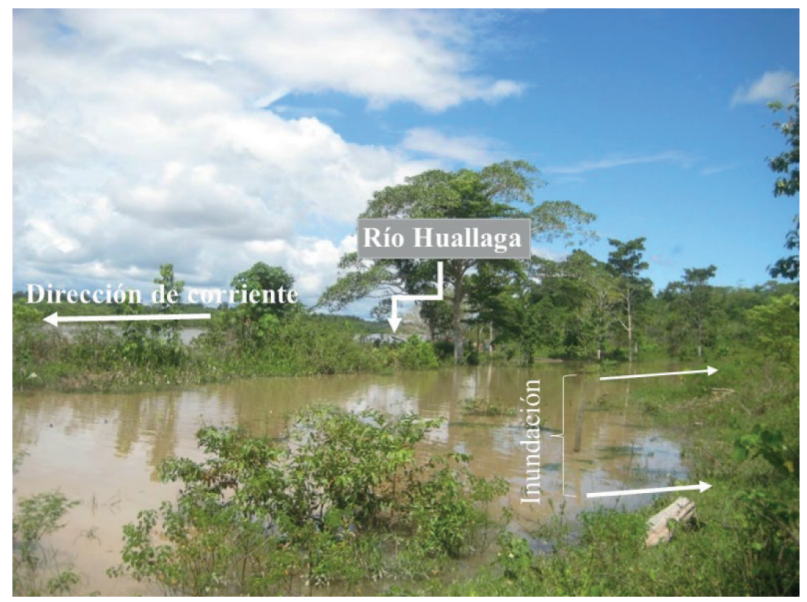

Figura 7: Inundación del río Huallaga, en su margen izquierda

Fuente: Ramos Robert, 2018

\section{Socavamientos y erosión lateral de riberas}

Son procesos erosivos que realizan las corrientes fluviales, ocurren fundamentalmente en el lado convexo de las "curvas" debido al ataque constante del agua, cuando esta incrementa su caudal y velocidad en donde transportan además materiales sólidos en suspensión. En estas zonas en donde el río va cambiando de dirección, las riberas son atacadas por la fuerza centrífuga que lleva la corriente. Por las dimensiones del río Huallaga, estos procesos son frecuentes también en diversos sectores del borde ribereño a lo largo de su curso.

Esta acción produce el progresivo ensanchamiento de los cauces y al retroceso de las riberas. Son acciones erosivas casi permanentes, que varían en intensidad de acuerdo a la época del año.

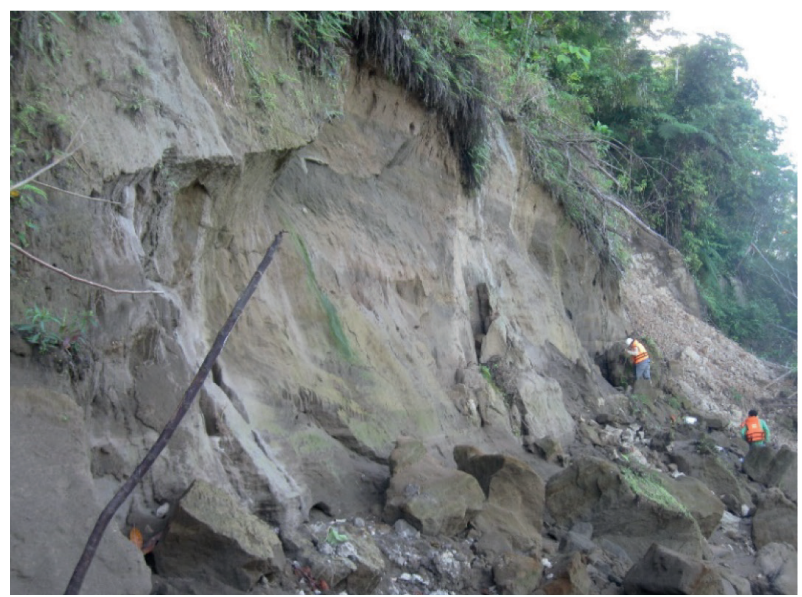

Figura 8: Socavamiento del río Huallaga, en las zonas de "curvas" Fuente: Ramos Robert, 2018

\section{Río Huallaga}

Por sus dimensiones presenta muchos afluentes importantes, destacando en su margen izquierda el río Chaupihuaranga, el río Monzón, el río Huayllabamba, el río Saposoa, el río Mayo que es el principal de ellos, así también otro río importante es el Paranapura. En la margen derecha destacan los ríos Tulumayo y Biabo (Carranza, 2011). El caudal promedio del río Huallaga es de $2969.5 \mathrm{~m}^{3} / \mathrm{s}$.

\section{Régimen hidrológico}

Para el análisis de la dinámica del río Huallaga se ha considerado los datos registrados en la estación Chazuta, esta estación presenta cuatro datos diarios (a las 6, 10, 14, y 18 horas) de los niveles de altura expresados en metros y a la vez en msnm (ANA, 2020). 


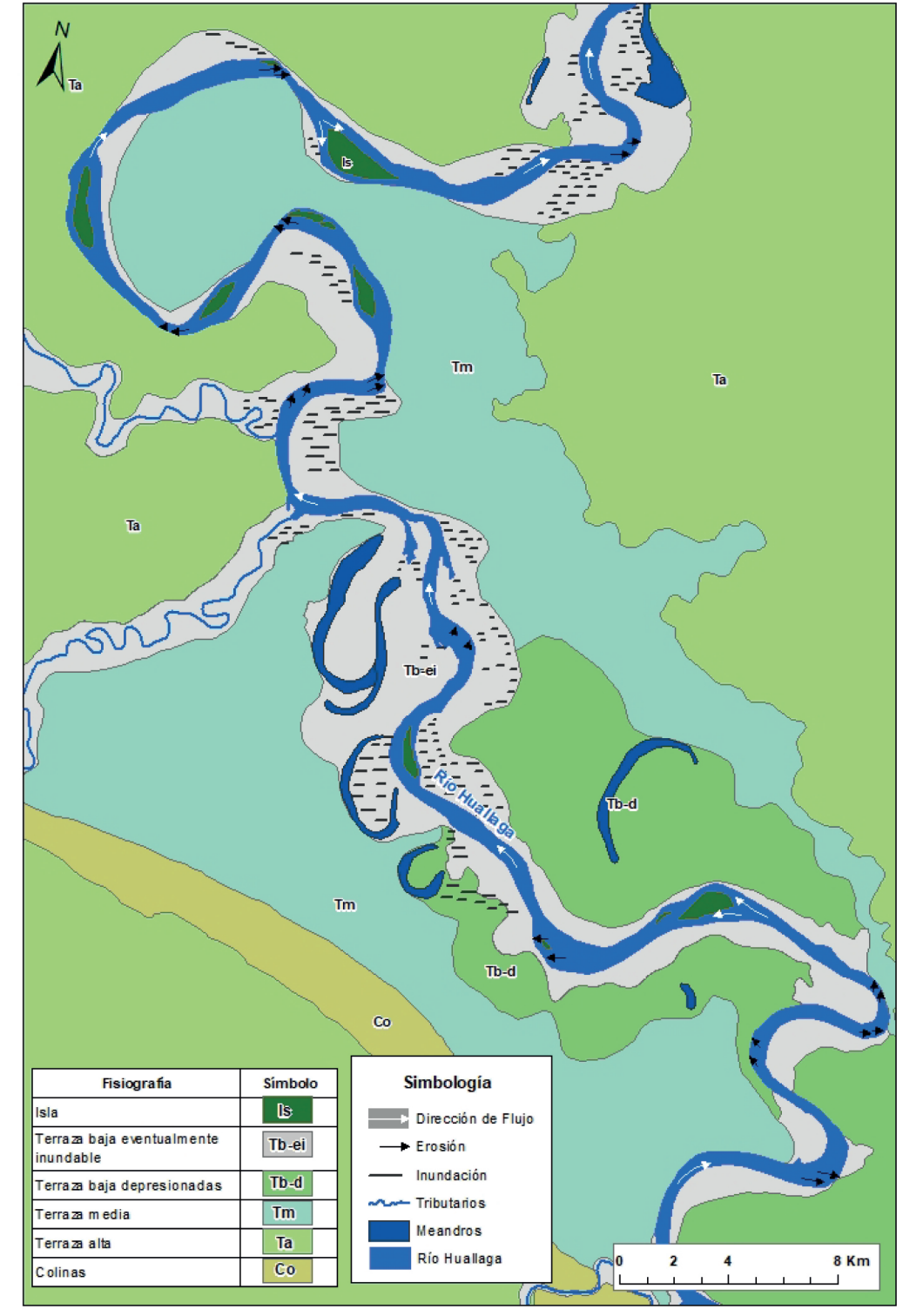

Figura 9: Mapa geomorfológico del área de investigación

Fuente: Ramos R. y Alva M., en base al análisis de imágenes de satélite Landsat y trabajo de campo

El nivel de altura del río sigue los patrones del régimen de la precipitación que ocurre en nuestro país (región andino-amazónica), así a partir de octubre la presencia de las masas de aire húmedas provenientes del Este Amazónico son más frecuentes por lo que la precipitación se va incrementando llegando a ser más intensos entre los meses de febrero y marzo, para luego disminuir paulatinamente hasta el mes de agosto. Esta dinámica se ve reflejada en la fluctuación del nivel de altura del río Huallaga aunque con un retraso debido a la propia conformación de la escorrentía superficial.
La altura promedio es de $130 \mathrm{msnm}$, es frecuente que entre los meses de marzo y abril puede superar incluso los $135 \mathrm{msnm}$, mientras que en los meses de estiaje (agosto-setiembre) puede estar por debajo de $127 \mathrm{msnm}$.

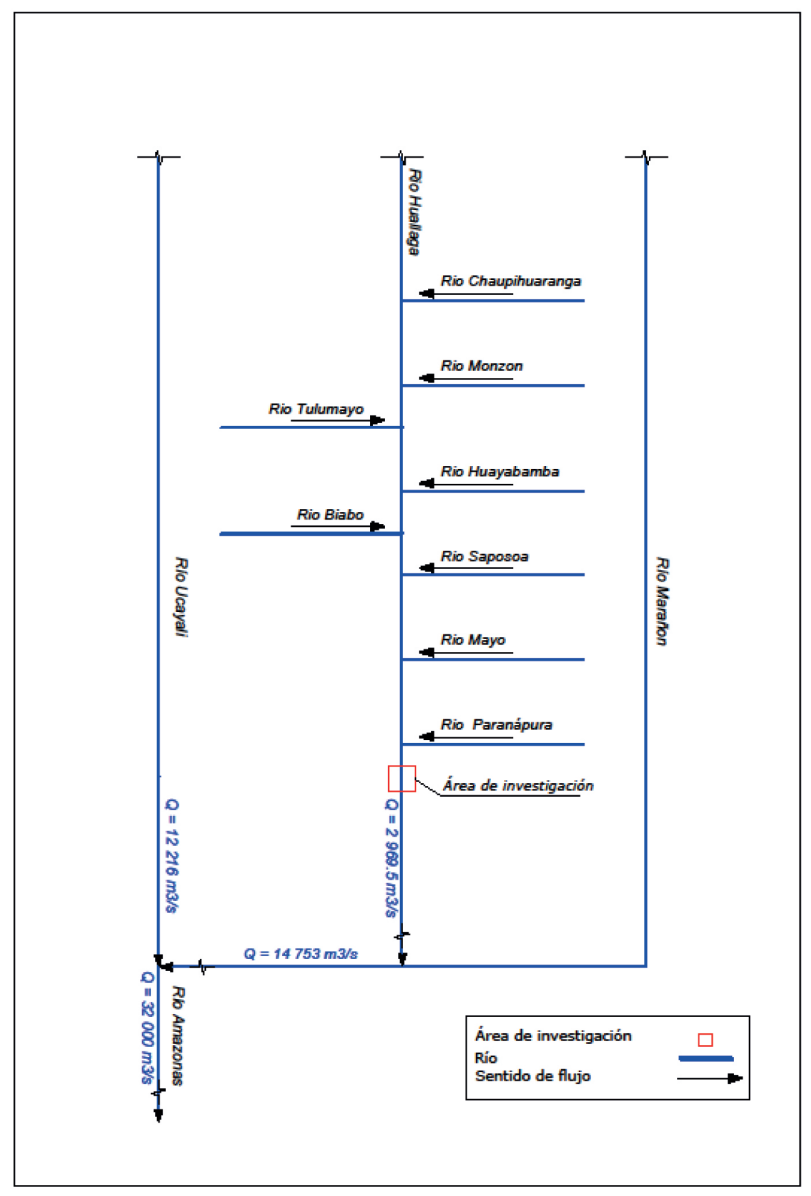

Figura 10: Diagrama de uno de los ríos amazónicos

Fuente: Ramos R. y Alva M.

Así mismo la estación Chazuta registra niveles de altura (período 2004-2018) expresados en metros (m), estableciéndose que el nivel promedio es de $12.4 \mathrm{~m}$, la altura máxima registrada es de $16 \mathrm{~m}$, mientras el nivel más bajo registrado es de 8.4, es decir que entre las crecidas máximas y la disminución que ocurre en los meses de estiaje, el nivel varían en un promedio de $8 \mathrm{~m}$.

La estación Chazuta registra también datos de caudales diarios, para esta investigación se cuenta con datos del período 2000-2013. Como ya se indicó el régimen anual responde a las lluvia que ocurren en la región andina y en la región amazónica, dada la extensión de la cuenca, los caudales se presentan 


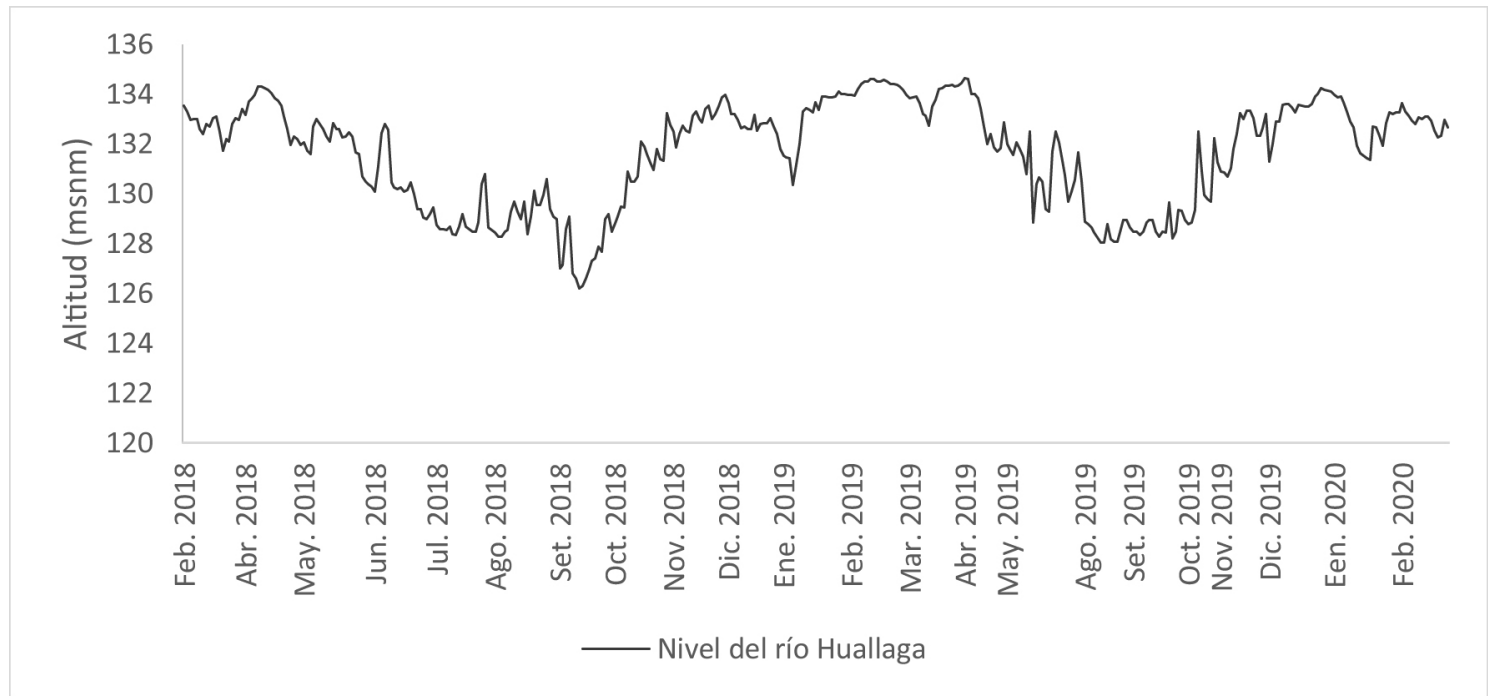

Figura 12: Nivel de altura del río Huallaga (msnm)

Fuente: Elaboración propia en base a datos de estación Chazuta.

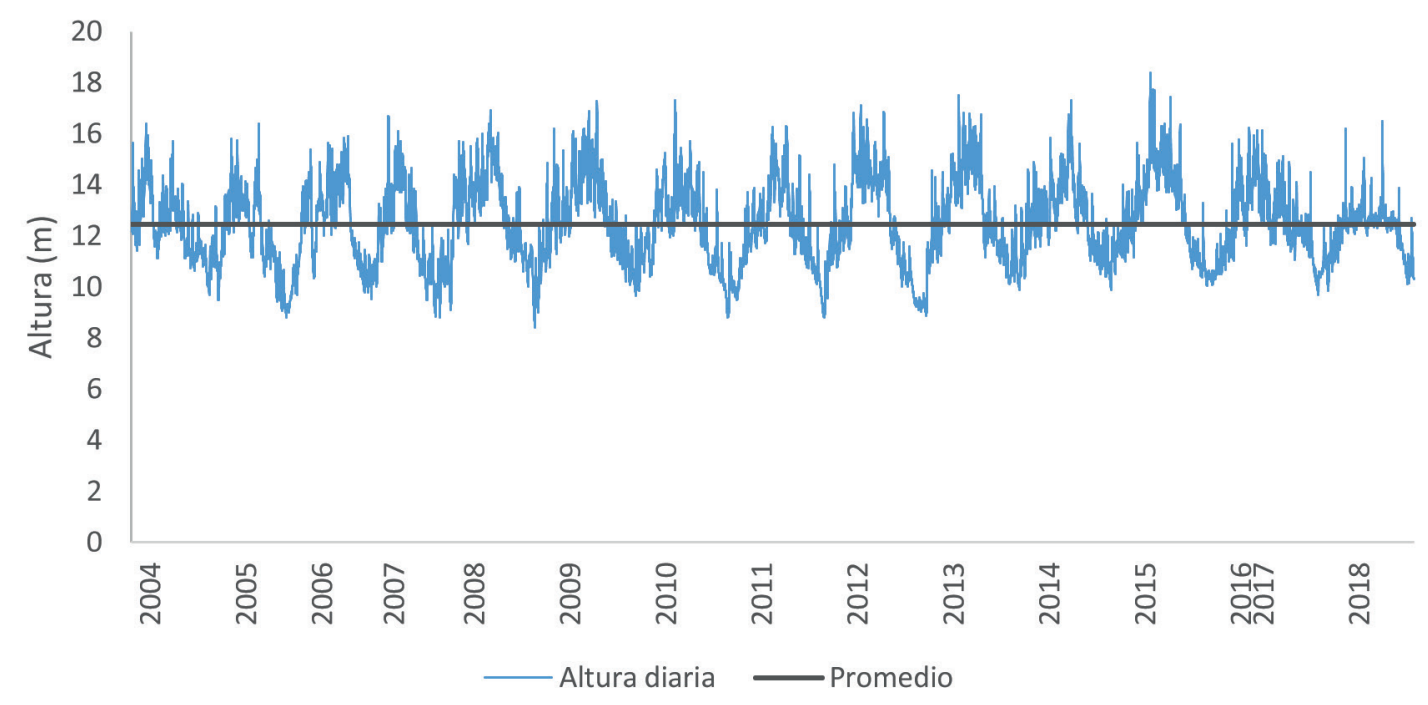

Figura 13: Altura del río Huallaga (m)

Fuente: Ramos R. y Alva M., en base a los datos de la estación Chazuta.

considerablemente elevados, con valores en época de avenida que superan los $5000 \mathrm{~m}^{3} / \mathrm{s}$, el caudal promedio es de $2969.5 \mathrm{~m}^{3} / \mathrm{s}$, mientras que en los meses de estiaje el caudal disminuye incluso por debajo de $1000 \mathrm{~m}^{3} / \mathrm{s}$.

El caudal diario del río Huallaga muestra valores considerablemente elevados como el ocurrido en el años 2007 en el donde el caudal supero incluso los $11000 \mathrm{~m}^{3} / \mathrm{s}$ y valores frecuentes que superan los 8 $000 \mathrm{~m} 3 / \mathrm{s}$, así mismo se evidencia caudales por debajo de $500 \mathrm{~m}^{3} / \mathrm{s}$, estos valores explicarían su dinámica, movilidad y la configuración constante del relieve aledaño.

\section{Características del lecho y velocidad superficial del río Huallaga}

Para caracterizar el lecho del río Huallaga se cuenta con un estudio de batimetría través de una Ecosonda Hidrográfico BATHY 500 DF de registro continuo en la zona de Muniches a unos $7 \mathrm{~km}$ aguas debajo de la ciudad de Yurimaguas, en esta zona el río 


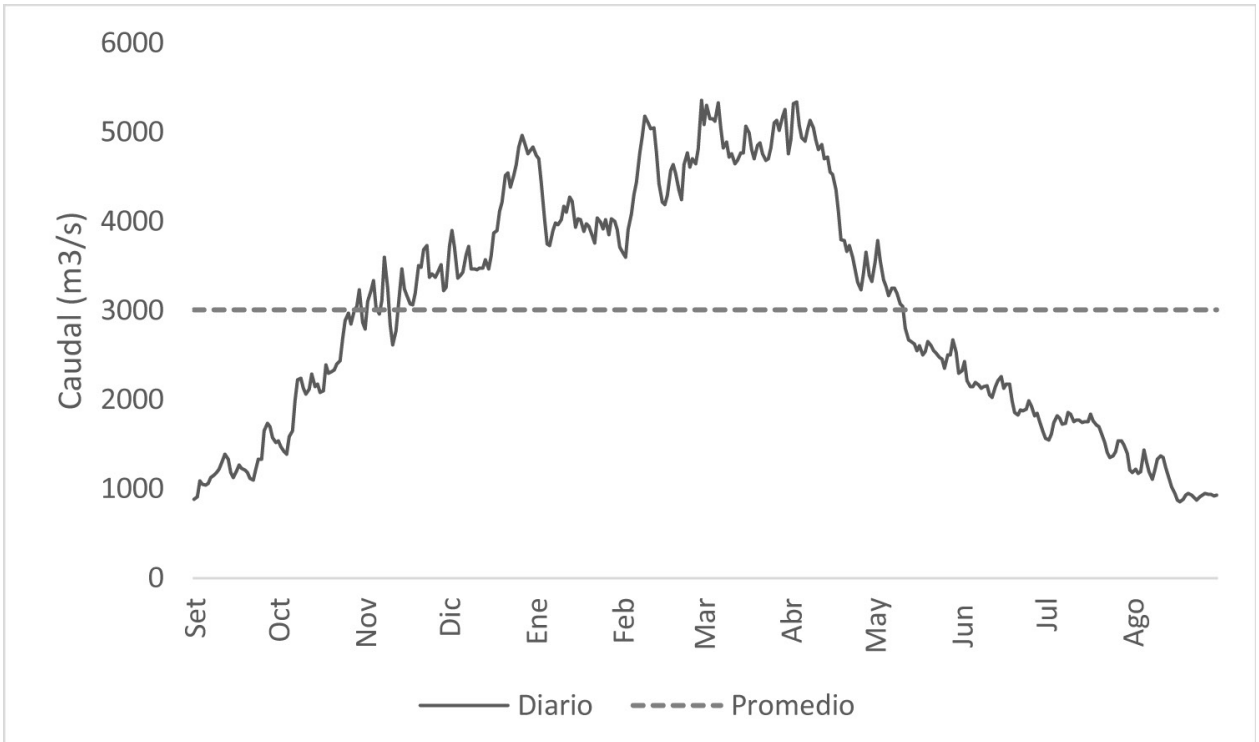

Figura 14: Caudal promedio diario y anual del río Huallaga $\left(\mathrm{m}^{3} / \mathrm{s}\right)$

Fuente: Ramos R. y Alva M., en base los datos de la estación Chazuta.

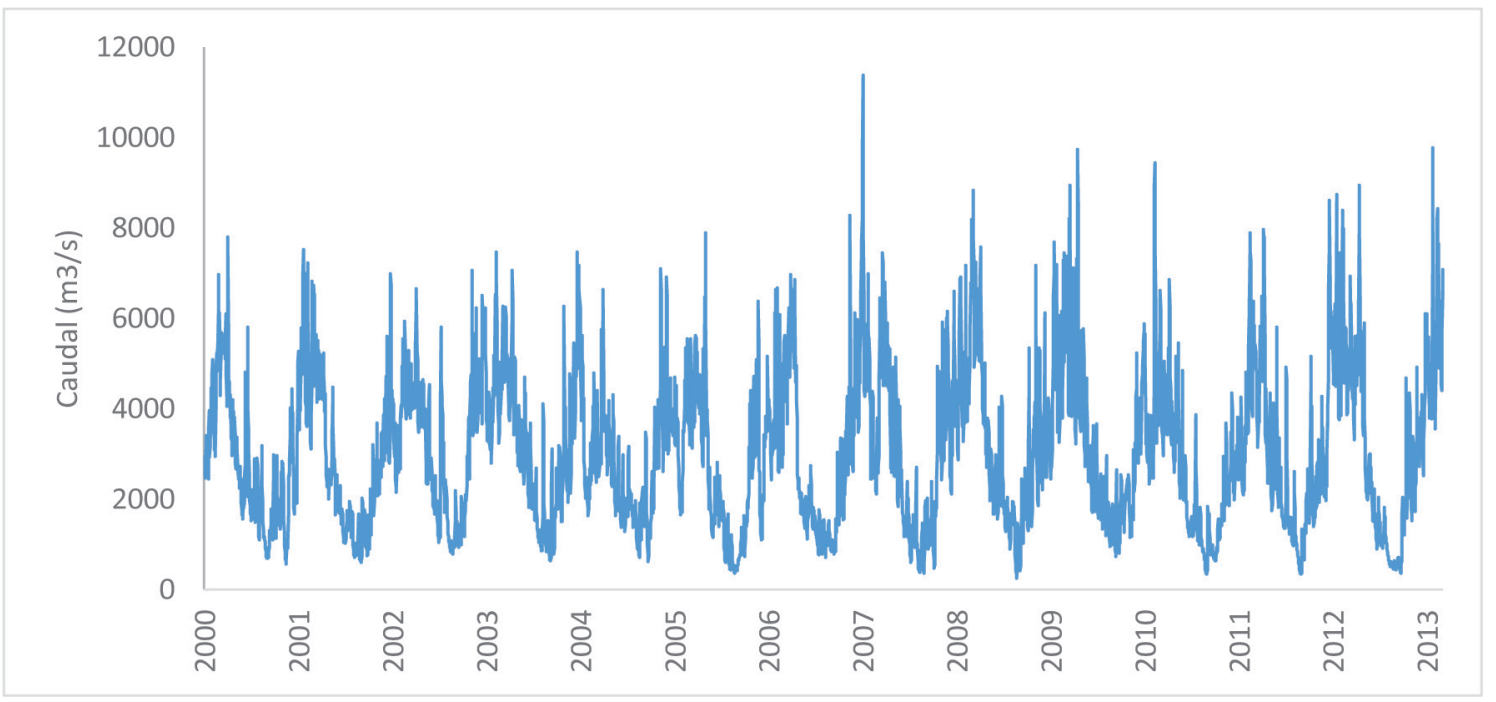

Figura 15: Caudal diario del río Huallaga $\left(\mathrm{m}^{3} / \mathrm{s}\right)$

Fuente: Ramos R. y Alva M., en base a los datos de la estación Chazuta.

tiene un ancho promedio de $325 \mathrm{~m}$. En general la profundidad varía desde 0.5 a $16 \mathrm{~m}$; en la margen izquierda has una distancia de $35 \mathrm{~m}$ la profundidad varía entre 0.5 a $11 \mathrm{~m}$ con una pendiente promedio de $34 \%$, en la zona central la profundidad oscila entre 12 a $16 \mathrm{~m}$ por lo que la pendientes es apenas de 5\% mostrando un lecho mucho más homogéneo. En la margen derecha hasta una distancia de $22 \mathrm{~m}$ la profundidad varía entre 0.5 a $12 \mathrm{~m}$, en esta sección la pendiente promedio es de $43 \%$. Por estas caracte- rísticas se puede establecer que el lecho muestra un perfil encajonado.

La velocidad superficial del río Huallaga se encuentra entre 2.16 y $2.32 \mathrm{~m}^{3} / \mathrm{s}$, esta varía en función a su ubicación, así en la zona central la velocidad es mayor mientras que en las zonas próximas a las márgenes esta disminuye debido a un mayor contacto con el lecho. 

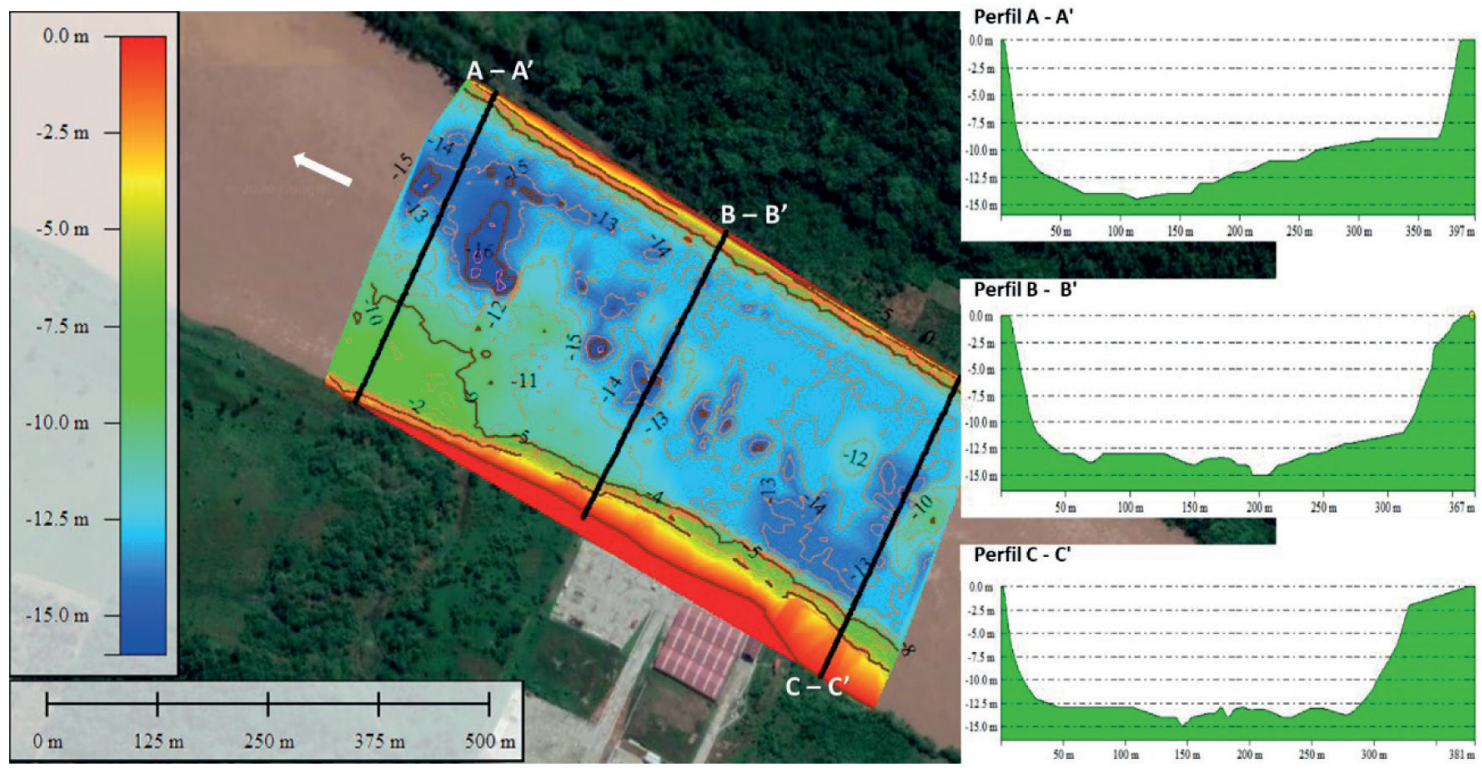

Figura 16: Profundidad y perfil del río Huallaga

Fuente: Ramos y Alva, en base a imágenes de satélite WorldView-3 de fecha 20 abril de 2020 y datos batimetria de fecha noviembre 2019.

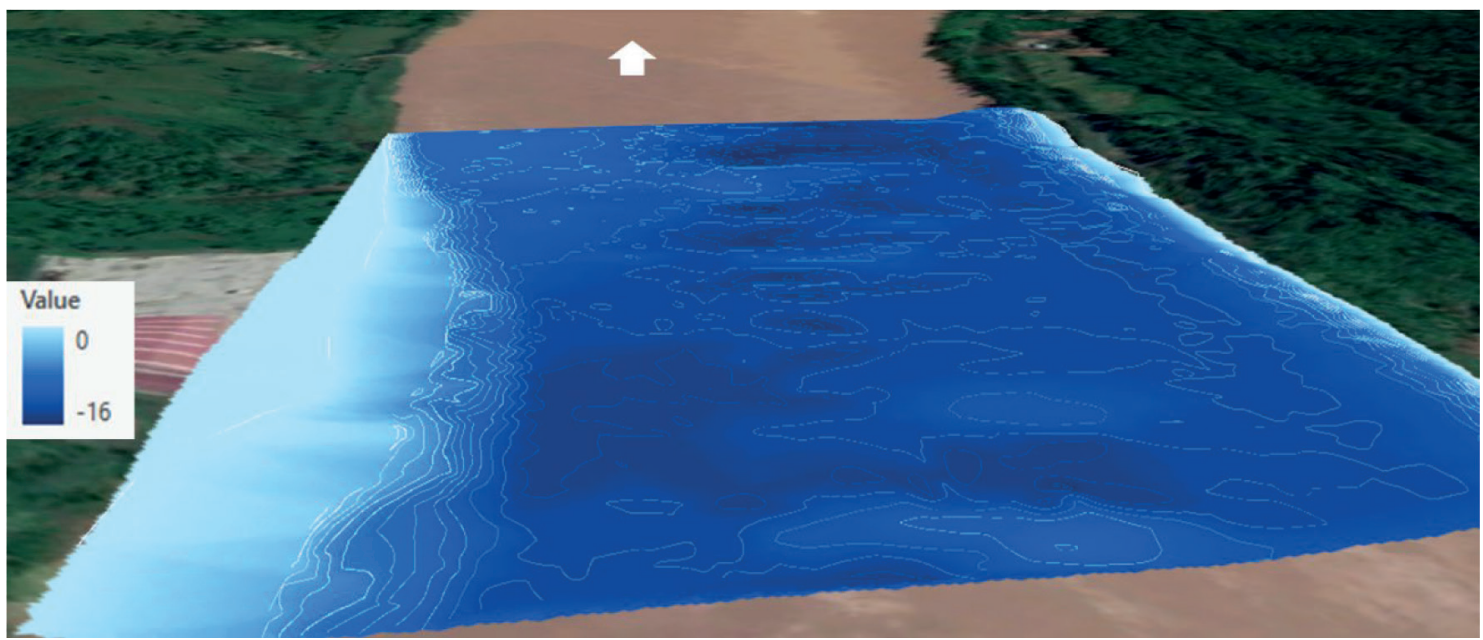

Figura 17: Perfil en 3D del río Huallaga

Fuente: Ramos y Alva, en base a imágenes de satélite WorldView-3 de fecha 20 abril de 2020 y datos batimetria de fecha noviembre 2019.

Perfil longitudinal de cauces de la llanura amazónica

Por las características topográficas de la llanura amazónica, el recorrido fluvial del río Huallaga tiene una tendencia natural a la sinuosidad. Este fenómeno representa en el río el mínimo consumo de energía y que su pendiente varíe a lo largo de su recorrido. En consecuencia, a medida que el flujo avanza, su pendiente disminuye gradualmente, así, esta disminución significa la pérdida de capacidad de arrastre de partículas, pérdida de poder de erosión del cauce y disminución del tamaño de partículas que arrastra (Morales, 2009).

Como ya se indicó, el río Huallaga se origina a más de 4500 msnm y el área de investigación se ubica a unos $130 \mathrm{msnm}$, esto origina una fuerte pendiente, en el sector alto de la cuenca, hay una gran capacidad de erosión y velocidades de la corriente que permiten el arrastre de partículas de mayor tamańo hacia aguas abajo. En las zonas intermedias, en donde la pendiente es más moderada, disminuye la velocidad y, por lo tanto, deposición de material grueso en el lecho flu- 


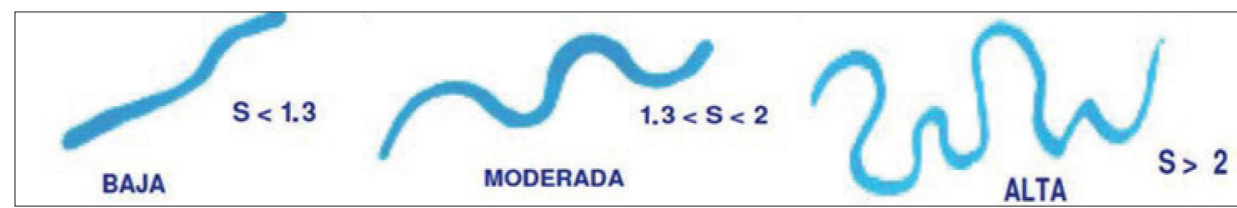

Fuente: Rocha, 2009

La sinuosidad del río Huallaga en el tramo de investigación es 1.6 lo que significa que es "Moderada".

\section{Dinámica fluvial de los ríos}

De acuerdo a Ollero (2007), la dinámica fluvial se refiere a complejos procesos activos y de metamorfosis de los sistemas fluviales, tanto en su componente espacial (a lo largo del eje fluvial, en su sección transversal y a nivel vertical) como en su evolución temporal.

Por lo que un río es un agente dinámico y que modifica el relieve constantemente en sus diversas variables, este dinamismo es consecuencia de la interacción de las variables climáticas, geológicas, geomorfológicas y la cobertura vegetal.

\section{Migración meándrica}

Es un proceso de cambio de dirección de los ríos cuando disminuye la velocidad del flujo de agua lo que ocasiona la colmatación y sedimentación del cauce, esto ocurren en gran medida por la escasa pendiente como es el que caracteriza a la llanura amazónica.

En el área de investigación los procesos de geodinámica fluvial son constantes y varían según el volumen del caudal del río Huallaga. Así en los años en donde se produce los caudales más elevados se evidencia los mayores procesos fluviales, por el contrario en los años en donde el incremento ha sido mínimo dicha dinámica es poco perceptible.

En esta investigación se han identificado cuatro zonas en donde la dinámica fluvial es significativa, que para estos fines se les ha identificado con la codificación 1, 2, 3 y 4, en cada una de ellos dichos procesos son variados tanto en su dimensión como en el proceso mismo, a continuación se presentan los resultados en cada zona:

Zona 1: En esta zona se desarrolla un proceso denominado socavamiento y erosión lateral que ocurre en una curva del río Huallaga, en su recorrido el río erosiona la zona convexa de su lecho, así desde 1973 hasta el 2019 la corriente ha erosionado esa sección del río logrando ampliar y modificar su cauce, esta variación ha sido de $631 \mathrm{~m}$ en donde el lecho se ha ampliado hacia la zona norte. Esto ha generado que en el lado concavo el lecho se ha haya desplazado 1 $189 \mathrm{~m}$ hacia el lado norte. En este período su lecho es de $1.7 \mathrm{~km}$.

Zona 2: En esta zona se ha identificado que la corriente varía en dos momentos, así entre 1973 a 1987 la dinámica del río ha sido relativamente estable con una variación mínima a ambas márgenes del río. Sin embargo desde 1987 al 2019 se evidencia una gran variación de dicha corriente y que en varios períodos el lecho del río ha cambiado su curso en determinadas zonas, esto podría deberse al proceso denominado neck cut-off en donde el río cambia su rumbo bruscamente (proceso ocurrido en 1987) y que el río al buscar su estabilidad estaría generando estas constantes variaciones en su dirección.

Zona 3: En esta zona ocurre el mismo proceso que en la Zona 1, en donde el río Huallaga al cambiar de dirección erosiona la ribera constantemente en su zona cóncava, en esta zona el socavamiento y erosión en lateral son más significativos evidenciándose que la margen izquierda el río se ha desplazado $1.7 \mathrm{~km}$ hacia su lado norte, mientras que la zona convexa el río se ha migrado $1.9 \mathrm{~km}$ también hacia la zona norte. En este período su lecho es de $2.2 \mathrm{~km}$.

El cambio de dirección del río se le denomina "avulsión", este es un proceso de migración en donde el flujo se desvía de un canal del río a un nuevo curso sobre la planicie de inundación adyacente (Slingerland \& Smith, 2004). A este desvío o corte del meandro se denomina cut off.

El proceso de chute cut-off es creado por la incisión de un nuevo canal a través de un point bar (Gagliano et al., 1984; Constantine, et al., 2010), este deja un acortamiento local del tramo del canal 
TABLa 2. Variación especial del río Huallaga en las zonas 1 y 3

\begin{tabular}{|c|c|c|c|c|}
\hline \multirow{2}{*}{ Año } & \multicolumn{2}{|c|}{ Zona 1 } & \multicolumn{2}{c|}{ Zona 3 } \\
\cline { 2 - 5 } & Variación $(\mathbf{m}) \mathbf{M D}$ & Variación $(\mathbf{m}) \mathbf{M I}$ & Variación $(\mathbf{m}) \mathbf{M D}$ & Variación $(\mathbf{m})$ MI \\
\hline $1973-1980$ & 156 & 218 & 473 & 308 \\
\hline $1980-1984$ & 85 & 143 & 175 & 139 \\
\hline $1984-1987$ & 35 & 80 & 25 & 110 \\
\hline $1987-1999$ & 311 & 143 & 550 & 532 \\
\hline $1999-2009$ & 26 & 511 & 161 & 289 \\
\hline $2009-2019$ & 18 & 94 & 524 & 1798 \\
\hline Total & 631 & 1189 & 1908 & \\
\hline
\end{tabular}

MI: Margen Izquierda

MD: Margen Derecha

Fuente: Ramos R. y Alva M.

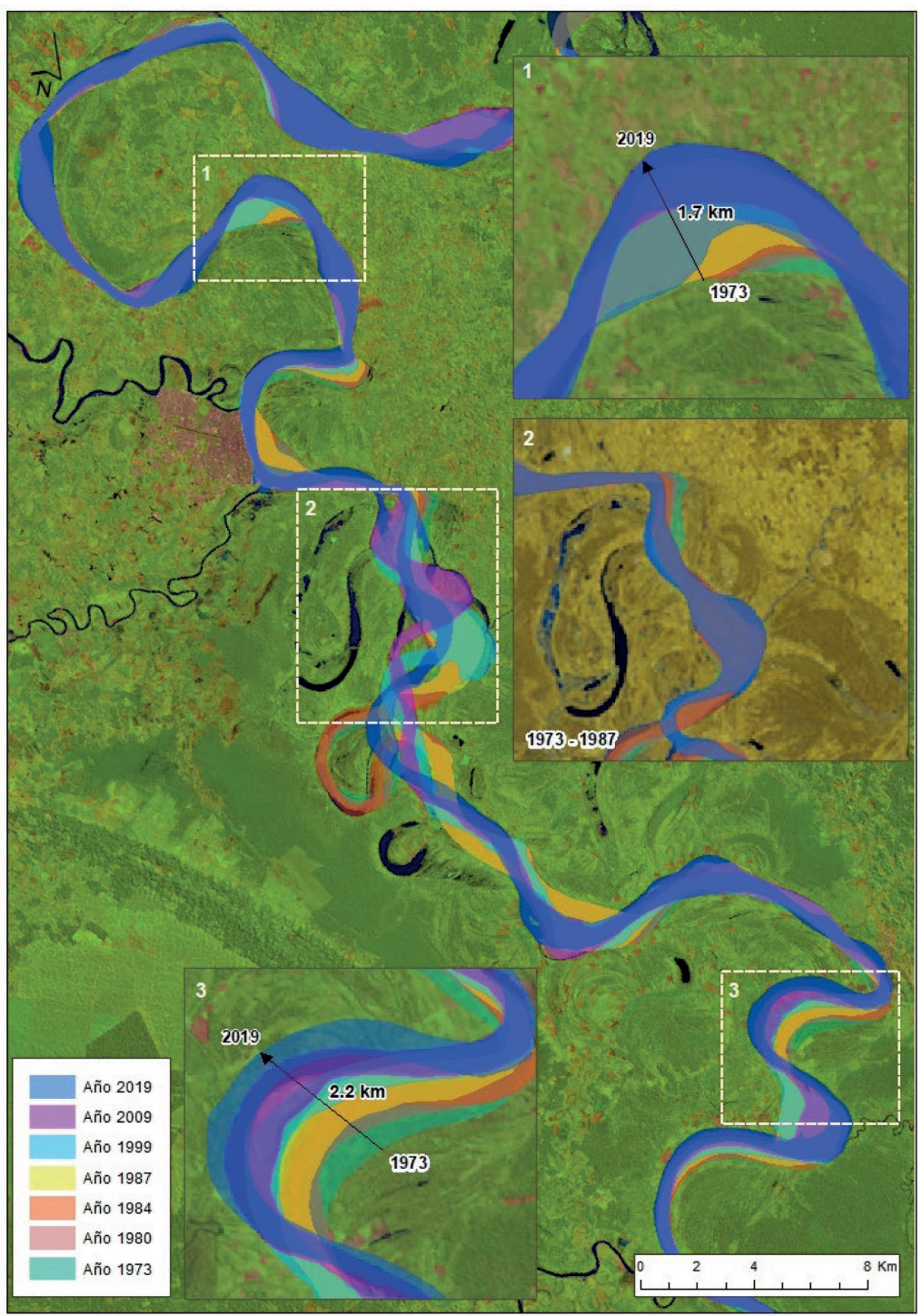

Figura 19: Procesos de dinámica fluvial río Huallaga

Fuente: Ramos R. y Alva M., en base a imágenes de satélite Landsat multitemporales y como consecuencia deja toda la curva aislada del canal principal.

El otro proceso de corte es el del neck cut-off, este se formaría a través de dos formas una por el excesivo crecimiento de la curva del meandro, y el otro, cuando dos meandros migran uno dentro de otro superponiéndose sobre sí mismos; posiblemente debido a una diferencia en la resistencia del material en dos meandros opuestos (Gagliano et al., 1984).

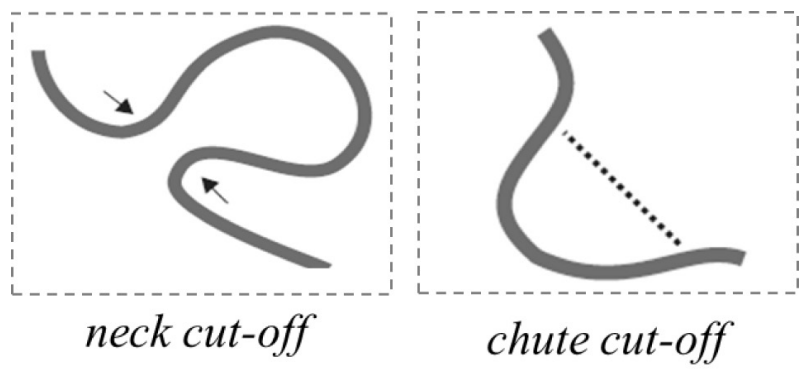

Esquema de los dos mecanismos de abandono de meandros: neck cut-off y chute cut-off.

Zona 4: En la actualidad en esta zona se evidencia un meandro abandonado, en donde hasta 1987 el río Huallaga tenía un curso definido por la misma, sin embargo por los constantes procesos denominado neck cut off se incrementó la curva del meandro hasta lograr definir un cauce nuevo a través del proceso chute cut off dejando abandonado y aislado respecto del canal principal. 


\section{Conclusiones}

En el área de investigación se han identificado cinco unidades fisiográficas, de estas las islas, terrazas bajas inundables y terrazas depresionadas están directamente afectadas por las crecidas de los ríos. Mientras que las terrazas medias y altas corresponden a depósitos antiguos que se encuentran exentos de dicha influencia. Mientras que las colinas corresponden a zonas elevadas y presentan una configuración diferente a las otras unidades.

Los procesos geodinamicos más frecuentes son la inundación que cubren grandes extensiones próximos al río Huallaga, se identifica también al socavamiento y erosión lateral que es más frecuente en las zonas en donde el río cambia de dirección.

El caudal promedio del río Huallaga es bastante importante, en los meses de avenida superan los $5000 \mathrm{~m}^{3} / \mathrm{s}$, el caudal promedio es de $2969.5 \mathrm{~m}^{3} / \mathrm{s}$, mientras que en los meses de estiaje el caudal disminuye incluso por debajo de $1000 \mathrm{~m}^{3} / \mathrm{s}$. en tanto que el caudal diario muestran una variabilidad mucho más notoria, así el caudal máximo supera los 11000 $\mathrm{m}^{3} / \mathrm{s}$ y valores frecuentes que superan los $8000 \mathrm{~m}^{3} / \mathrm{s}$, así mismo se evidencia caudales por debajo de 500 $\mathrm{m}^{3} / \mathrm{s}$.

El ancho promedio del río Huallaga es de 325 m, pudiendo ampliarse más en algunos sectores, la profundidad es variable, desde la superficie, en las márgenes la profundidad cambia bruscamente hasta una profundidad aproximada de 14 , hacia la zona central alcanza una profundidad máxima de $16 \mathrm{~m}$ la velocidad superficial es de $2.2 \mathrm{~m}^{3} / \mathrm{s}$.

En el período analizado se identifica que en el año 1987 el río Huallaga cambio su curso dejando su cauce abandonado a modo de meandro. Así mismo en las zonas en donde el río cambia de dirección se evidencia que, esta presenta una movilización de su cauce hacia la zona norte.

\section{Bibliografía}

Almeida L., Sourdat M. (1982). Génesis geológica y morfológica de la Amazonia, sus aplicaciones actuales para el desarrollo de la región. Instituto Panamericano de Geografía e Historia.

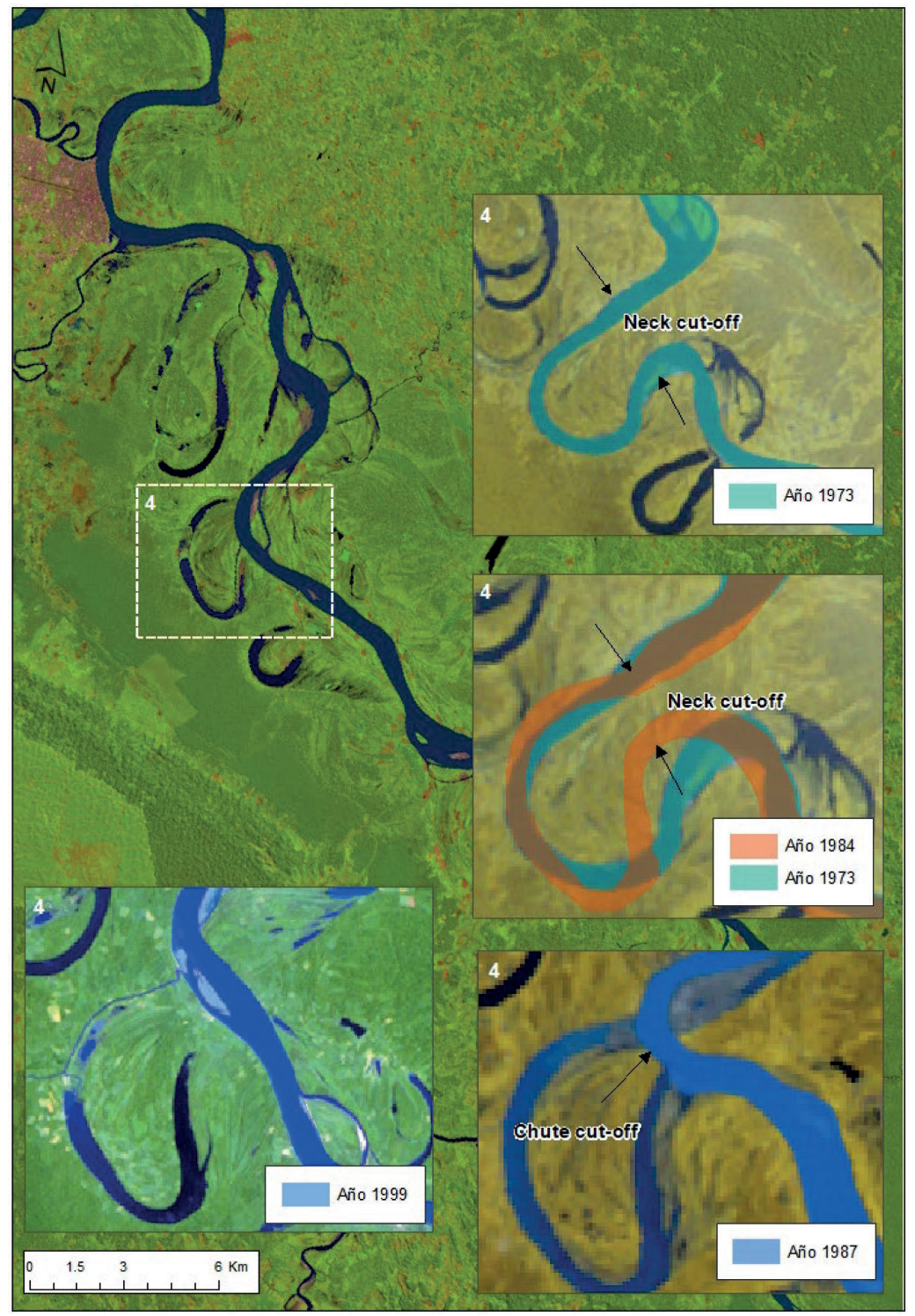

Figura 20: Proceso de migración del río Huallaga

Fuente: Ramos R. y Alva M., en base a imágenes de satélite Landsat multitemporales

ANA (Autoridad Nacional del Agua). https://www.ana. gob.pe/portalsnirh/portada. Consulta Marzo, 2020.

Carranza, J. (2011). Evaluación hidrológica de las cuencas amazónicas peruanas. SENAMHI.

Constantine, J. A., McLean, S. R., \& Dunne, T. (2010). A mechanism of chute cutoff along large meandering rivers with uniform floodplain topography. Geological Society of America Bulletin, 122(5-6), 855-869.

Espinoza J., Ronchail J., Guimberteau M., Guyot J., Lavado W. y Santini W. (2014). Eventos hidrológicos extremos en la cuenca amazónica peruana: presente y futuro. IRD Editions. 
Gagliano, S. and Howard, P. (1984). The neck cutoff oxbow lake cycle along the lower mississippi river. In River Meandering (pp. 147-158). ASCE.

Guneralp, I., Abad, J., Zolezzi, G., and Hooke, J. (2012). Advances and challenges in meandering channels research. Geomorphology, 163, 1-9.

Gutiérrez, E. (2008). Geomorfología. Universidad de Zaragoza. pp 2.

Leopold, L., Wolman, M. (1957). River cannel patterns: braided, meandering and straigh. U.S. Geological Survey Professional Paper, 282 pp.

Maza, J., García, M. (2011). Estabilización y rectificación de ríos. UNAM.

Meade, R., Dunne, T., Richey, J., Santos, U., Salati, E., et al. (1985). Storage and remobilization of suspended sediment in the lower amazon river of Brazil. Science, 228(4698), 488-490.

Molinier, M., Guyot, J.-L., de Oliveira, E., \& Guimares, V. (1996). Les régimes hydrologiques de l'Amazone et de ses affluents. L'hydrologie tropicale: géoscience et outil pour le développement. IAHS Publ., 238: 209-222.

Morales, R. (2009). Diagnóstico del comportamiento histórico del río Ichilo en el área de Puerto Villarroel (Tesis de Maestría). Cochabamba: Universidad Mayor de San Simón. Consulta: Diciembre 2015.

Ollero, A. (2007). Algunos apuntes sobre la dinámica fluvial: Los rios actuales como resultado de su propia libertad y la intervención humana en sus riberas. Researchgate, Universidad de Zaragoza.

Paredes, M. (2014). Estado de alerta de los ríos amazónicos. Servicio Nacional de Meteorología e Hidrología. SENAMHI.

Rocha, A., (2009). La morfología fluvial y su incidencia en la estabilidad de las obras viales. VIII Congreso Internacional Obras de Infraestructura Vial.

Slingerland, R. and Smith, N. (2004). River avulsions and their deposits. Annu. Rev. Earth Planet. Sci., 32, 257-285.

Solórzano, B. (2011). Procesos fluviomorfológicos de relevancia en el río Tahuamanu en el ámbito del Puente Tahuamanu. Lima: UNI.

Villota, H. (2005). Geomorfología aplicada a levantamientos edafológicos y zonificación física de tierras. Bogotá: Instituto Geográfico Agustín Codazzi. Oficina CIAF.

USGS (Science for a changing world). https://earthexplorer.usgs.gov/ Consulta, enero 2020. 